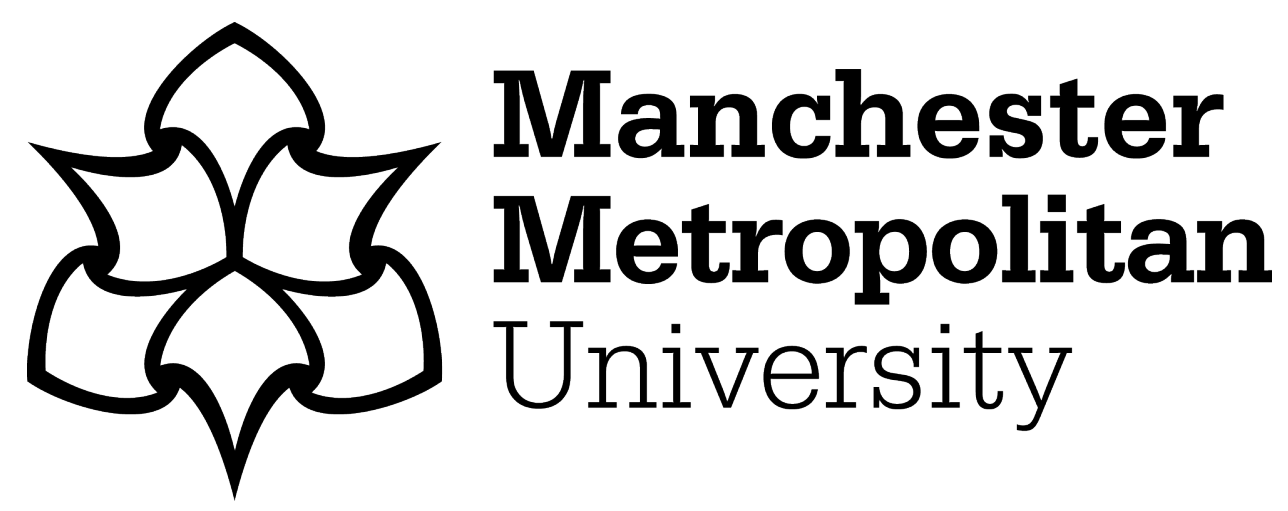

Sarwar, M and Haider, J (2011) Characteristics and machining performance of TiN and TiAIN coatings on a milling cutter. In: International Conference on Advances in Materals and Processing Technologies (AMPT2010), 24 October 2010 - 27 October 2010, Paris, France.

Downloaded from: https://e-space.mmu.ac.uk/622526/

DOI: https://doi.org/10.1063/1.3552310

Please cite the published version 


\title{
Characteristics and Machining Performance of TiN and TiAlN Coatings on a Milling Cutter
}

\author{
Mohammed Sarwar and Julfikar Haider
}

School of CEIS, Ellison Building, Northumbria University, Newcastle Upon Tyne, NE1 8ST, UK

\begin{abstract}
Titanium Nitride (TiN) coating deposited by Physical Vapour Deposition (PVD) or Chemical Vapour Deposition (CVD) techniques on cutting tools (single point or multipoint) has contributed towards the improvement of tool life, productivity and product quality [1]. Addition of $\mathrm{Al}$ in TiN coating (e.g., TiAlN or AlTiN) has further improved the coating properties required for machining applications $[2,3]$. This work presents a comparative investigation on TiN and TiAlN coatings deposited on to a Powder Metallurgy High Speed Steel (PM HSS) milling cutter used for machining bimetal (M42 + D6A) steel strips. PVD (Arc evaporation) technique was used to deposit the coatings after carefully preparing the cutting edges of the milling cutter. Microstructure, chemical composition, hardness and adhesion of the coatings have been characterised using different characterisation techniques. The incorporation of Al into TiN coating results in an improvement in hardness, wear resistance and cutting performance. Examination of the worn flank in the coated cutting edges revealed that abrasive and adhesive wear are the predominant failure mechanisms. Tool designers, coating suppliers and manufacturing engineers could be benefited from the information provided.
\end{abstract}

Keywords: TiN, TiAlN, Coating, Milling cutter, Machining

PACS: 81.15.Cd; 81.20.Wk

\section{INTRODUCTION}

Specially designed solid milling cutters made from PM HSS are employed for economic manufacturing of saw teeth in bimetal strips. The cutting edges of the milling cutter deteriorate after short production runs and the cutter needs to be resharpened in order to restore the sharp cutting edges. Therefore, cutting edges of the milling cutter must withstand for longer production runs to improve the productivity and product quality. Over the past decades, it has been established $[1,3,4]$ that TiN coating on both single and multipoint cutting tools improves tool life, machining performance and product quality due to its high hardness, low coefficient of friction, good adhesion etc. Inspired by the success of TiN coating on cutting tools, a programme of study has been initiated to coat the milling cutters by PVD TiN coating, which resulted considerable improvement in tool life and workpiece quality [5]. However, it has also been demonstrated that coatings developed by the addition of $\mathrm{Al}$ in TiN coating (i.e., TiAlN) can further enhance the performance of cutting tools in different machining applications $[2,3,6,7]$. Currently no information is available in the public domain about the cutting performance of coated milling cutters used for manufacturing saw tooth. The closest operation found in the literature is gear hobbing, 
where successes have been reported with TiAlN coating over TiN [8-10]. The current paper deals with the comparative investigation of properties and performance of TiN and TiAlN coatings on a milling cutter used for machining bimetal strips.

\section{EXPERIMENTAL DETAILS}

Approximately half the length of a cylindrical HSS milling cutter was coated by TiN and the other half was coated by TiAlN (Figure 1a). The coatings were deposited by Arc evaporation technique with a deposition temperature of approximately $450{ }^{\circ} \mathrm{C}$. The coating thickness varies from 3-5 $\mu \mathrm{m}$. Coating morphology and chemical composition were obtained by a Scanning Electron Microscope (SEM) and Energy Dispersive X-ray Spectroscopy (EDS). The crystal structure of the coatings was characterised by glancing angle X-ray diffraction (XRD) technique at an angle of incidence of $2^{\circ}$. Hardness of the coatings were measured by Vickers microhardness tester. Adhesion quality of the coatings was evaluated qualitatively using a Rockwell $\mathrm{C}$ indenter under a load of $150 \mathrm{~kg}$. The damage patterns around the indentation were observed by an optical microscope and compared with the adhesion scale of HF1 (best adhesion) to HF6 (poor adhesion).
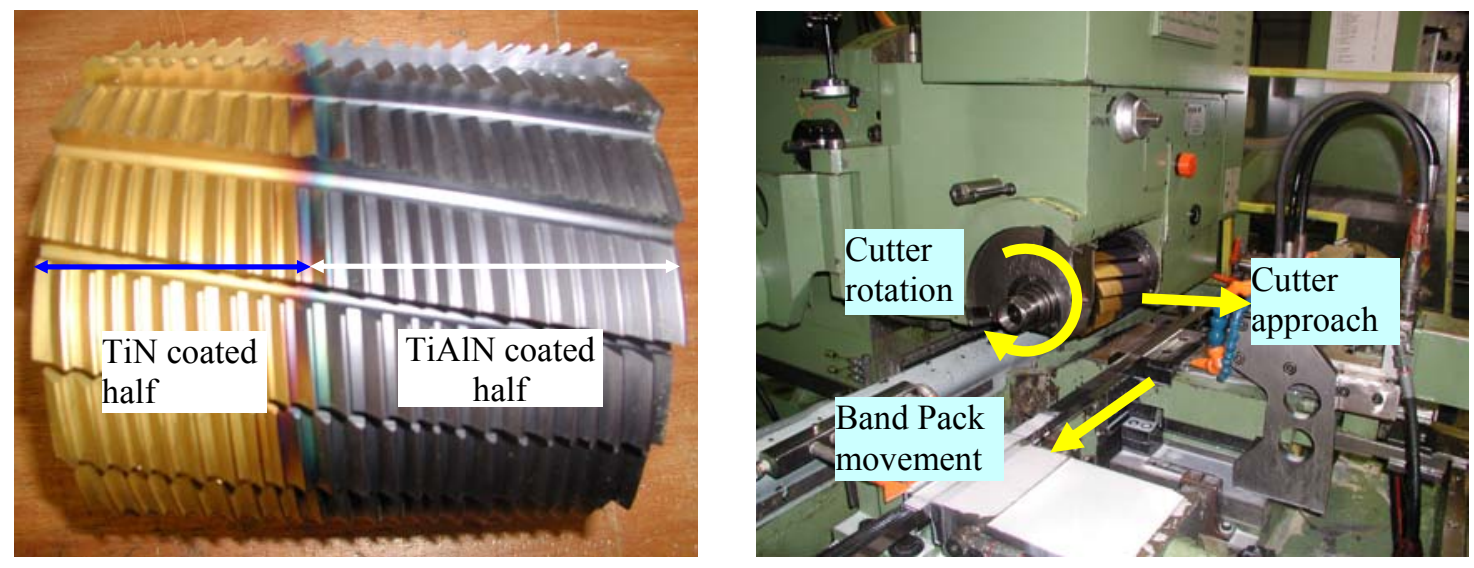

FIGURE 1. (a) Half-length coated milling cutter and (b) milling test with the coated cutter.

The performance of the TiN and TiAlN coatings were analysed by machining annealed bimetal steel (M42 HSS edge wire welded to D6A steel backing material) with the coated milling cutter in a CNC milling machine (Figure 1b). The machining test was conducted by milling 600 passes without any regrinding of the cutter and milling another 300 passes after regrinding of the cutter. TiN and TiAlN coated teeth of the milling cutter at the new, worn (300 and 600 milling passes) and reground (after 300 passes) conditions were examined by a Compact Video Microscope (Allen CVM; magnification $50 \times$ ). At the new condition, TiN and TiAlN coated cutting edges of the milling cutter were sharp (edge radius: 9-10 $\mu \mathrm{m}$ ) with no burrs. The cutting edges, rake and clearance faces were fully covered with coatings having no sign of substrate exposure owing to flaking of the coating. Flank wear in the milling cutter teeth was measured by an Image analysis software (Motic Image plus 2.0) after taking the picture of the cutter teeth by the Compact Video Microscope. 


\section{RESULTS AND DISCUSSIONS}

\section{Coating Properties}

The surface morphologies of both coatings in SEM exhibited pores and microparticles (Figure 2), which are characteristics of cathodic arc evaporation process used for the coating deposition. EDS analysis showed that atomic percentage in TiN coating $(51.59 \% \mathrm{Ti}$ and $48.41 \% \mathrm{~N})$ and TiAlN coating $(28.56 \% \mathrm{Ti}, 22.52 \% \mathrm{Al}$ and $48.92 \% \mathrm{~N}$ ) were very close to stoichiometric values. In TiAlN coating, the amount of Ti (56\%) was slightly higher than $\mathrm{Al}(44 \%)$.
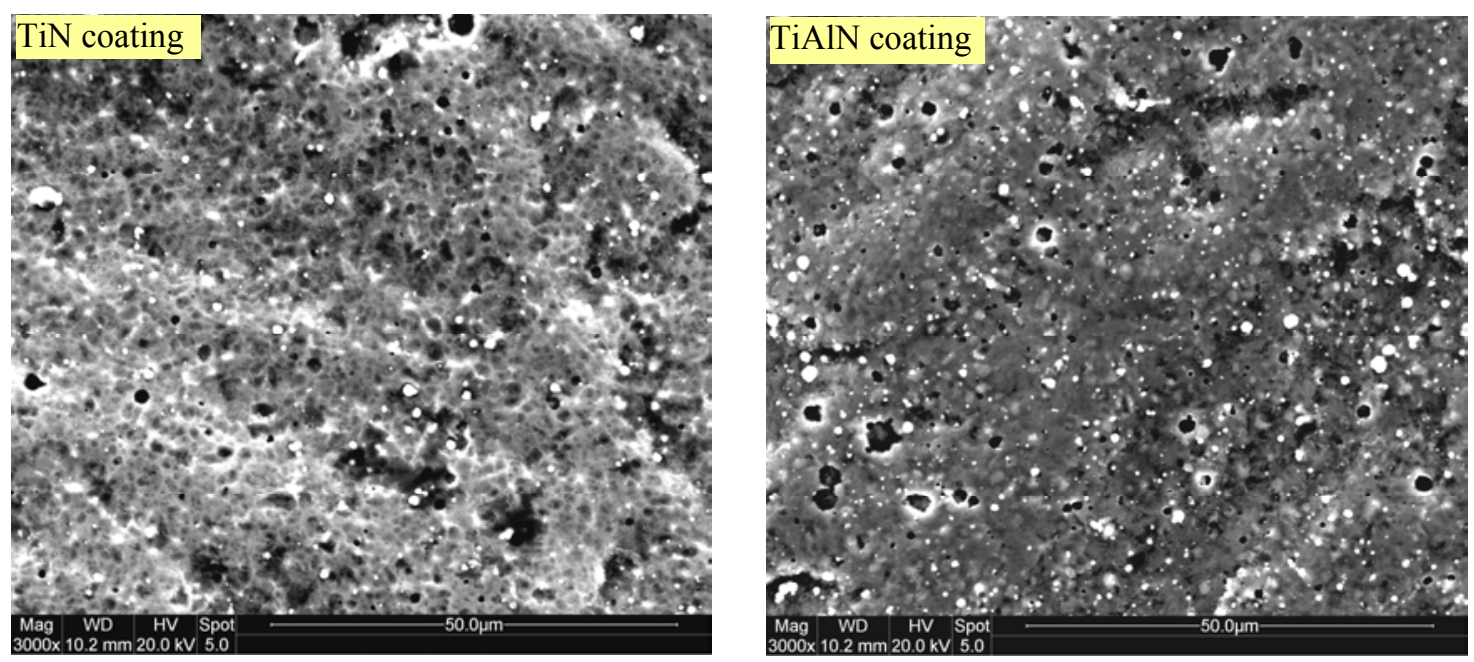

FIGURE 2. Surface morphologies of TiN and TiAlN coatings in SEM.

XRD analysis demonstrated that both TiN and TiAlN coatings have similar crystallographic orientations as shown in Fig. 10. However, the peak positions shifted to higher angles in TiAlN coating when compared to TiN coating. This phenomenon indicated that alloy nitride TiAlN formed and the lattice parameter decreased in TiAlN coating due to the substitution of larger Ti atoms in TiN lattice by smaller Al atoms. Similar results have also been reported by other investigators [11]. TiN and TiAlN coatings showed typical $\mathrm{NaCl}$ type crystal structure (i.e., face centered cubic) with a strong orientation in (111) and (200) directions respectively [7]. However, significant reduction of the intensity of the (111) peak was observed in TiAlN coating. This indicated that $\mathrm{Al}$ addition in TiN coating also promoted the refinement of crystal structure [12].

Hardness measurement revealed that TiAlN coating (3300 HV) possessed significantly higher hardness than TiN coating $(2300 \mathrm{HV})$. The higher hardness in TiAlN coating could be related to the structural modification took place due to the incorporation of $\mathrm{Al}$ in TiN [13]. Both coatings didn't show any indication of adhesive failure as no circular cracks or spallation were found around the Rockwell $\mathrm{C}$ indentation. Therefore, the adhesion of the coatings can be considered as HF1 (best adhesion). 


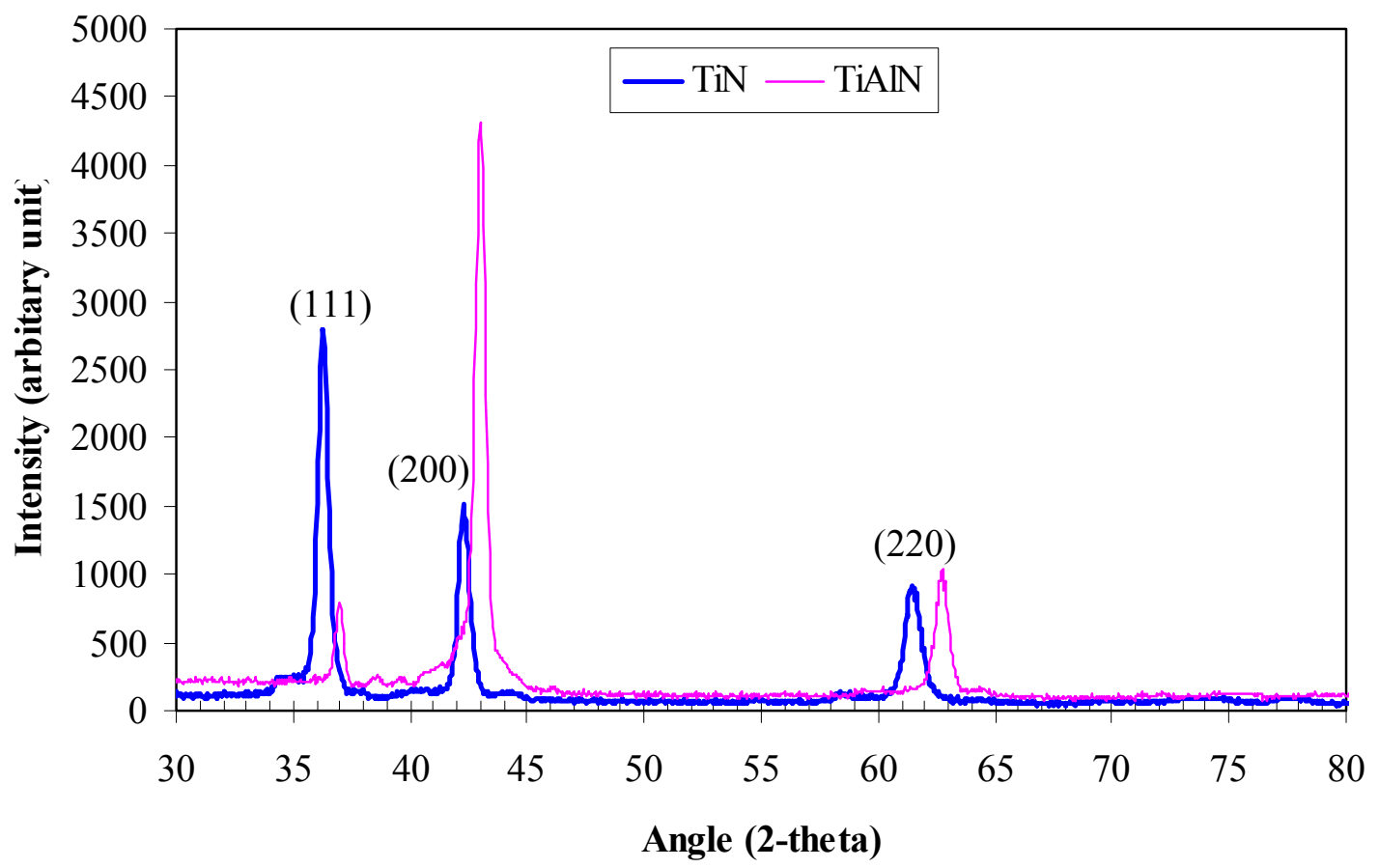

FIGURE 3. X-Ray diffraction patterns of TiN and TiAlN coatings.
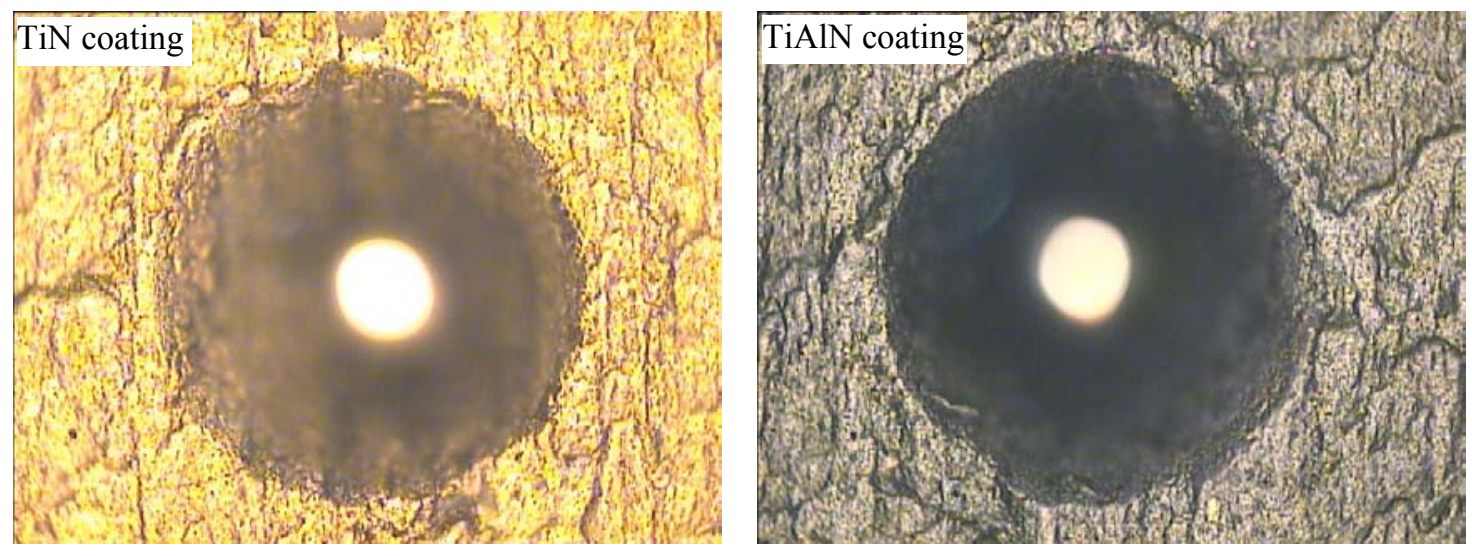

FIGURE 4. Micrographs of Rockwell C indentations in TiN and TiAlN coatings $(200 \times)$.

\section{Flank Wear Measurement}

Figure 6 presents the flank wear in TiN and TiAlN coated teeth after 300 and 600 milling passes from the new condition of the cutter and 300 passes from the reground condition of the cutter. Both at new and reground conditions of the cutter, TiAlN coated teeth showed smaller flank wear compared to TiN coated teeth. The higher hardness, toughness and wear resistance of the TiAlN coating compared to TiN coating could be the reason for lower flank wear in TiAlN coated teeth [8]. However, it should be noted that for the same number of milling passes (300 passes), TiAlN coated teeth performed best at the new condition of the cutter where the coating was on both rake face and clearance face compared to the reground cutting edges. This was 
because of the absence of coating on the rake face and lack of cutting edge sharpness at the reground condition compared to the new condition.

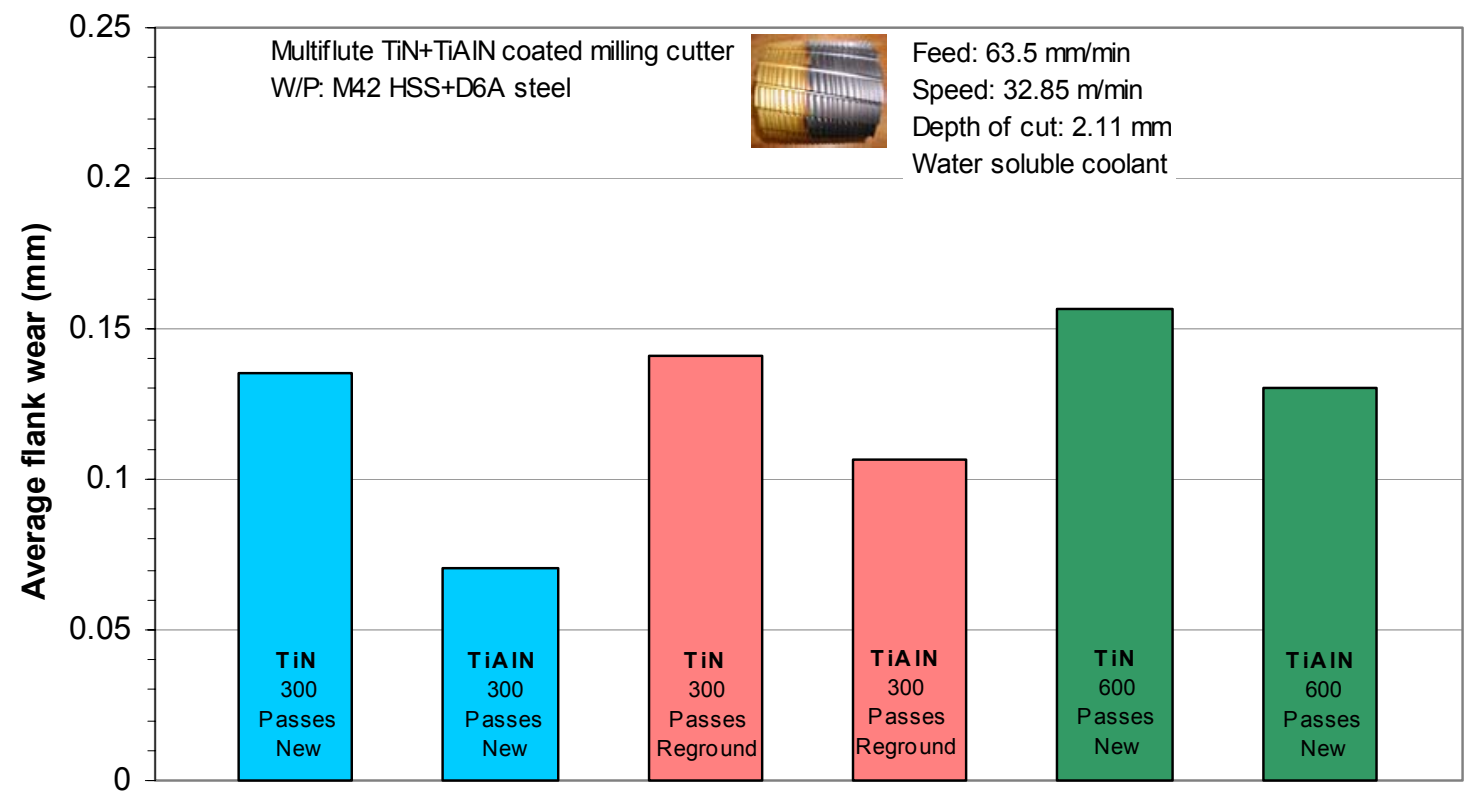

FIGURE 5. Average flank wear in TiN and TiAlN coated teeth.

\section{Wear Modes and Mechanisms}

Flank wear has been identified as the principal wear mode in both TiN and TiAlN coated teeth of the cutter as presented in Figure 6. Other researchers [14] have also drawn same conclusions while machining annealed steel by a HSS milling cutter. The maximum flank wear in TiAlN coated teeth appeared at the wedge area and gradually decreased along the cutting edges compared to more uniform flank wear along the cutting edges of $\mathrm{TiN}$ coated teeth.
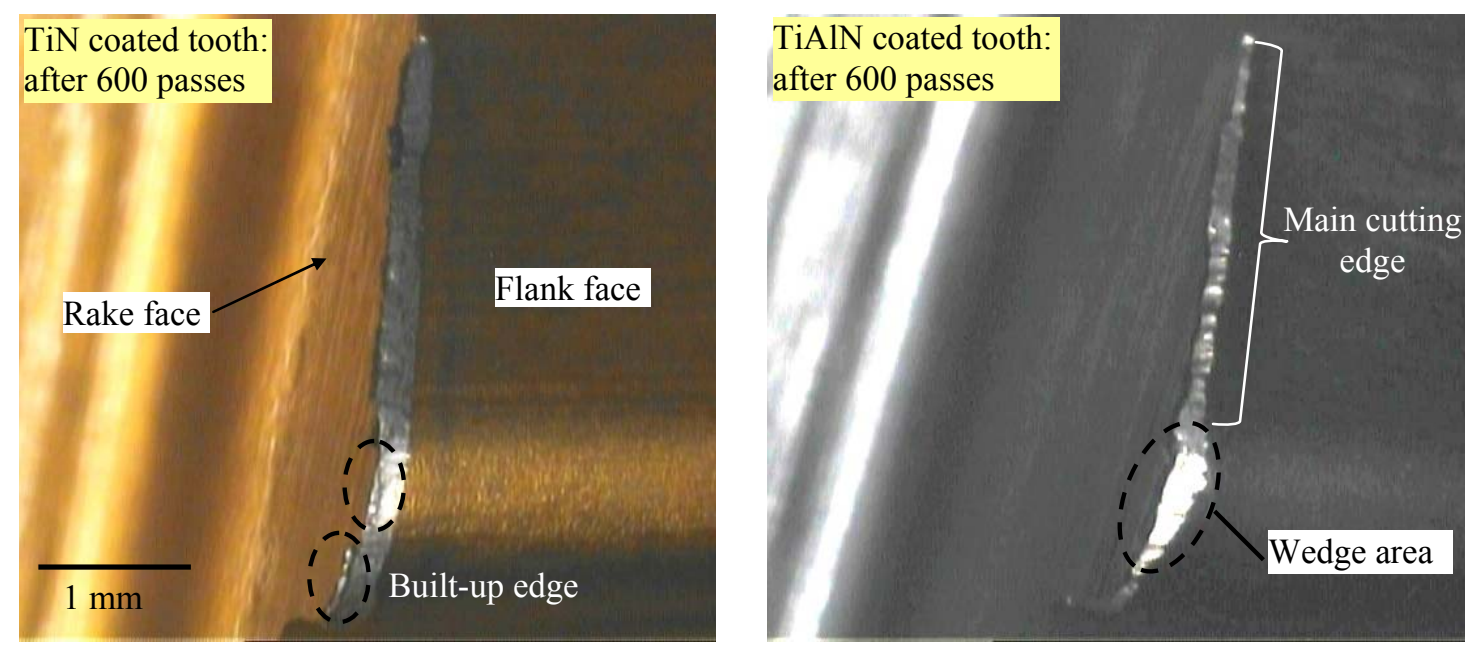

FIGURE 6. Conditions of TiN and TiAIN coated teeth after 600 milling passes.

The flank wear was developed due to the gradual removal of coatings by the abrasive action between the tool material and machined workpiece material. The flank 
wear then propagated by the removal of coating fragments of almost full coating thickness from the free edge of the coatings [10]. The hard particles from the workpiece or coating fragments play a major role in the progression of flank wear [8]. Strong evidences of BUEs formation were found in both TiN and TiAlN coated teeth (Figure 6), but to a lesser extent in the latter. Built-up edge (BUE) was formed by the strong adherence or welding of the soft workpiece material to the cutting edges. When BUEs reached a critical point, they were broken intermittently with the fragments of cutter material and removed with the chip.

\section{CONCLUSIONS}

Surface morphologies of TiN and TiAlN coatings deposited on a milling cutter featured with microholes and microparticles, typical of cathodic arc deposition process. XRD analysis confirmed that both coatings possessed face centered cubic crystal structure with an indication of alloy nitride formation in TiAlN coating due to the substitution of $\mathrm{Ti}$ atoms by $\mathrm{Al}$ atoms. Therefore, a significant increase of hardness in the TiN coating resulted compared to TiN coating. The coatings were well adhered on the sharp and burr free cutting edge as evidenced in Rockwell $\mathrm{C}$ adhesion test. The direct comparison of the performance of the coatings in milling test with the halflength coated cutter revealed that TiAlN coating exhibited higher wear resistance than TiN coating. Irregular flank wear was found to be the dominant mode of wear in both TiN and TiAlN coated teeth. The abrasive wear and adhesive wear with built-up edge formation were the governing mechanisms of flank wear in coated teeth.

\section{ACKNOWLEDGEMENT}

The authors gratefully acknowledge the support from the tool manufacturing company and the School of CEIS, Northumbria University, UK to carry out this work.

\section{REFERENCES}

1. M. Sarwar, D. Gillibrand and S.R. Bradbury, Surf. Coat. Technol. 41, 443-450 (1991).

2. S. PalDey and S.C. Deevi, Mater. Sci. Eng. A342, 58-79 (2003).

3. W. Kalss, A. Reiter, V. Derflinger, C. Gey and J.L. Endrino, Int. J. Refract. Met. Hard Mater. 24, 399-404 (2006).

4. M. Sarwar, Surf. Coat. Technol. 108-109, 612-619 (1998).

5. M. Sarwar, J. Haider, M. Persson and H. Hellbergh, Int. Conf. Surf. Coat. Nanostruct. Mater. (NanoSMat 2008) Barcelona, Spain, (2008) p.70.

6. M. Arndt and T. Kacsich, Surf. Coat. Technol., 163-164, 674-680 (2003).

7. L. Chen, Y. Dua, S.Q. Wang, A.J. Wang and H.H. Xua, Mat. Sci. Eng. A 502, 139-143 (2009).

8. J. A. B. O. dos Santos, W. F. Sales, S. C. Santos, A. R. Machado, M. B. da Silva, J. Bonney and E. O. Ezugwu, Int. J. Adv. Manuf. Technol. 31, 629-637 (2007).

9. M. Zlatanović and P. Stošić, Vacuum. 39, 557-562 (1989).

10. J. Gerth, M. Larsson, U.Wiklund, F. Riddar and S. Hogmark, Wear. 266, 444-452 (2009).

11. S-Y. Yoon, J.-K. Kim and K.H. Kim, Surf. Coat. Technol. 161, 237-242 (2002).

12.X. Ding, C.T. Bui and X.T. Zeng, Surf. Coat. Technol. 203, 680-684 (2008).

13.P.W. Shum, W.C. Tam, K.Y. Li, Z.F. Zhou and Y.G. Shen, Wear 257, 1030-1040 (2004)

14.K.L. Rutherford, S.J. Bull, E.D. Doyle and I.M. Hutchings, Surf. Coat. Technol. 80, 176-180 (1996). 